\title{
A randomized trial to evaluate the effect of a trace mineral premix on the incidence of active digital dermatitis lesions in cattle
}

\author{
A. Gomez, ${ }^{* 1}$ N. Bernardoni, ${ }^{*}$ J. Rieman, ${ }^{*}$ A. Dusick, ${ }^{*}$ R. Hartshorn, ${ }^{*}$ D. H. Read,† M. T. Socha, $\ddagger$ N. B. Cook, ${ }^{*}$ \\ and D. Döpfer* \\ *School of Veterinary Medicine, University of Wisconsin, 2015 Linden Drive, Madison 53706-1102 \\ †California Animal Health and Food Safety Laboratory System, School of Veterinary Medicine, University of California-Davis, San Bernardino \\ Branch, 105 W. Central Avenue, San Bernardino 92408-2113 \\ łZinpro Corporation, 10400 Viking Dr., Ste. 240, Eden Prairie, MN 55344
}

\section{ABSTRACT}

A balanced, parallel-group, single-blinded randomized efficacy study divided into 2 periods was conducted to evaluate the effect of a premix containing higher than typically recommended levels of organic trace minerals and iodine (HOTMI) in reducing the incidence of active digital dermatitis (DD) lesions acquired naturally and induced by an experimental infection challenge model. For the natural exposure phase of the study, 120 healthy Holstein steers 5 to 7 mo of age without signs of hoof disease were randomized into 2 groups of 60 animals. The control group was fed a standard trace mineral supplement and the treatment group was fed the HOTMI premix, both for a period of $60 \mathrm{~d}$. On d 60, 15 steers free of macroscopic DD lesions were randomly selected from each group for the challenge phase and transported to an experimental facility, where they were acclimated and then challenged within a DD infection model. The same diet group allocation was maintained during the $60 \mathrm{~d}$ of the challenge phase. The primary outcome measured was the development of an active DD lesion greater than $20 \mathrm{~mm}$ in diameter across its largest dimension. No lesions were identified during the natural exposure phase. During the challenge phase, $55 \%(11 / 20)$ and $30 \%(6 / 20)$ of feet were diagnosed with an active DD lesion in the control and treatment groups, respectively. Diagnosis of DD was confirmed by histopathologic demonstration of invasive Treponema spp. within eroded and hyperplastic epidermis and ulcerated papillary dermis. All DD confirmed lesions had dark-field microscopic features compatible with DD and were positive for Treponema spp. by PCR. As a secondary outcome, the average DD lesion size observed in all feet was also evaluated. Overall mean (standard deviation) lesion size was $17.1(2.36) \mathrm{mm}$ and 11.1 (3.33) $\mathrm{mm}$ for the control and treatment groups,

Received December 27, 2013.

Accepted June 2, 2014.

${ }^{1}$ Corresponding author: artgomez01@gmail.com respectively, with this difference being driven by acute DD lesions $>20 \mathrm{~mm}$. A trend existed for the HOTMI premix to reduce the total DD infection rate and the average size of the experimentally induced lesions. Further research is needed to validate the effect of this intervention strategy in the field and to generate prevention and control measures aimed at optimizing claw health based on nutritional programs.

Key words: digital dermatitis, experimental challenge, organic trace minerals

\section{INTRODUCTION}

Bovine digital dermatitis (DD), also called papillomatous digital dermatitis (PDD) or foot warts, is a contagious disease of the feet of cattle that responds to antibiotics, found worldwide (Blowey and Sharp, 1988; Read and Walker, 1998a). The precise etiology of DD is undefined. However, compelling evidence exists that several phylotypes of Treponema spp. play an important role in its pathogenesis (Read et al., 1998; Gomez et al., 2012). Prolonged exposure to slurry in the environment and poor foot hygiene predispose cattle to development of DD (Rodriguez-Lainz et al., 1999; Somers et al., 2005). The disease has a high incidence in countries with intensive cattle husbandry (Holzhauer et al., 2006; USDA, 2009) and DD-associated lameness results in significant economic and welfare problems, particularly in the dairy industry (Bruijnis et al., 2010; Cha et al., 2010; Ettema et al., 2010). Numerous efforts have been made to prevent and control DD, currently including strategies based on frequent use of disinfecting footbaths at the herd level (Jorritsma et al., 2007; Holzhauer et al., 2008) and topical treatments of acute DD lesions for individual animals (Dreher et al., 1999; Berry et al., 2010; Loureiro et al., 2010). However, these strategies have obtained variable success (Relun et al., 2013). In a cross-sectional study including 22,454 adult cows in 383 herds, single-herd prevalence was reported as high as $83 \%$, with an average of $21.2 \%$ of the cows 
affected (Holzhauer et al., 2006). Furthermore, the traditional approach to help prevent DD infection has overlooked animals receiving less attention with regard to lameness, such as beef or replacement dairy heifers. However, evidence exists to suggest that replacement dairy cattle should be a primary focus for DD management in dairy herds. Laven and Logue (2007) showed that heifers infected with DD before calving were more susceptible to DD infection during lactation. Similarly, Holzhauer et al. (2012) reported an increased average risk (odds ratio) of 5.97 of recurrent or persistent lesions during the first lactation in animals previously diagnosed with DD during the rearing period and Capion et al. (2009) reported a 15\% DD prevalence in heifers before parturition. One of the limitations to control DD in young animals is the lack of adequate facilities to implement footbaths and treat individual cases in addition to a significant increase in labor. Therefore, the development of management strategies aimed at optimizing the immune response to DD and increasing skin quality of the foot are attractive components of an integrated approach to DD control.

Thus, one approach to enhance disease resistance of cattle in general is to provide an adequate supply of available trace minerals, such as $\mathrm{Zn}, \mathrm{Mn}, \mathrm{Cu}$, or $\mathrm{I}$. Zinc is of importance in maintaining the health and integrity of skin due to its role in cellular repair and replacement, and has a critical role in wound healing (Moynahan, 1981; Miller et al., 1988). Zinc and Mn also help regulate a wide variety of immune system components, including those of $\mathrm{T}$ lymphocytes, natural killer cells, IL-2, IL-6, and tumor necrosis factor $\alpha$ (Wirth et al., 1984; Pinna et al., 2002; Ibs and Rink, 2003). Both cell-mediated and humoral immunity are greatly depressed by $\mathrm{Cu}$ deficiency (Prohaska and Failla, 1993). In addition, low $\mathrm{Cu}$ status in steers was associated with a reduced response of peripheral-blood lymphocytes to stimulation with T-cell mitogens following weaning and IBRV challenge (Gengelbach et al., 1997; Wright et al., 2000), and I affects the local inflammatory response and the ability of macrophages to form the cytotoxic compounds that kill phagocytized pathogens (Klebanoff and Clark, 1978; Siddiqui et al., 1993). Furthermore, the trace mineral uptake depends on the form trace minerals are offered in the diet and, therefore, conditioning the level of trace mineral requirements achieved (Wedekind et al., 1992).

An important gap exists in the research of alternative strategies to manage young stock in relation to DD. Aiming at preventing DD in heifers, the use of elevated levels of organic trace minerals (OTM) and iodine might be an easily implemented management strategy that might increase the success of systematic prevention and control of DD at the herd level.
In the current study, the objective was to evaluate the efficacy of a trace mineral premix containing higher than typically recommended levels of OTM and iodine (HOTMI) in reducing the incidence of naturally and experimentally induced DD lesions in a randomized controlled trial in Holstein steers.

\section{MATERIALS AND METHODS}

The study was approved before commencement by the School of Veterinary Medicine Animal Care and Use Committee under Protocol No. V-1429 and issued by the Research Animal Resources Center of the University of Wisconsin-Madison.

\section{Trial Design}

We conducted a balanced, parallel-group, singleblinded randomized efficacy study divided into 2 periods (natural exposure phase and challenge phase). The study was conducted between January and April 2010. The natural exposure phase corresponded to the first $60 \mathrm{~d}$ after enrollment and aimed to evaluate the efficacy of the HOTMI premix in preventing natural DD infection. The challenge phase corresponded to 60 to 120 d after enrollment, and aimed to evaluate the efficacy of the HOTMI premix in preventing the occurrence of experimentally induced active DD lesions (Figure 1).

\section{Study Groups (Participants)}

Holstein steers purchased from a local custom steerraising operation were selected to be part of the study and were eligible if they appeared healthy by clinical inspection and had a BW between 135 and $270 \mathrm{~kg}$. The steers were excluded if a DD lesion was diagnosed on any of the 4 feet after inspection in a restraint chute. During the natural exposure phase, the steers were housed at a commercial rearing operation in 4 group pens in a naturally ventilated building with a bedded pack system and free water and feed access. During the challenge phase, the steers were housed in a closed building under positive pressure ventilation in 2 slatted floor pens, with free water and feed access at the Livestock Laboratory of the University of WisconsinMadison. Feed was offered once per day in both locations.

\section{Interventions}

Natural Exposure Phase. One hundred twenty steers were randomly allocated into 2 groups of 60 and fed for a period of $60 \mathrm{~d}$ HOTMI premix containing OTM (Availa 4; Availa Zn; Zinpro Corp., Eden Prairie, MN) 


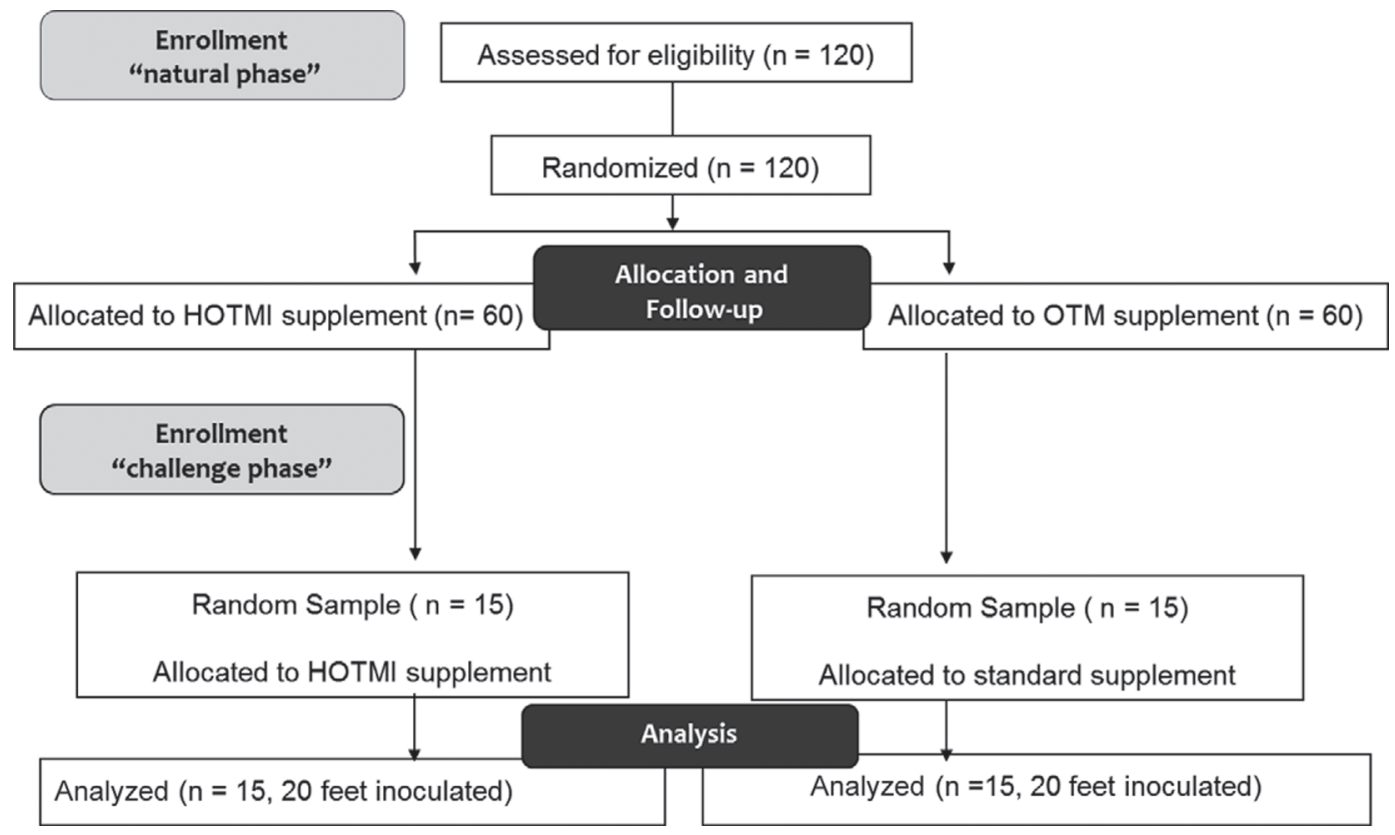

Figure 1. Flow diagram of the trial, including natural exposure and challenge phases and number of animals allocated to the supplement with higher than typically recommended levels of organic trace minerals and iodine (HOTMI) and the standard mineral supplement. OTM $=$ organic trace minerals.

and ethylenediamine dihydroiodide (EDDI; treatment group) or a standard trace mineral supplement (Cargill Inc., Minneapolis, MN; control group). The HOTMI was formulated to provide daily (per $45 \mathrm{~kg}$ of BW) 103 $\mathrm{mg}$ of $\mathrm{Zn}, 68 \mathrm{mg}$ of $\mathrm{Mn}, 14 \mathrm{mg}$ of $\mathrm{Cu}, 1.1 \mathrm{mg}$ of $\mathrm{Co}, 4$ $\mathrm{mg}$ of $\mathrm{I}$, and $0.32 \mathrm{mg}$ of Se. Metal amino-acid complexes (Zinpro Corp.) supplied 59.2, 24.6, and 76.9\% of the Zn, $\mathrm{Mn}$, and $\mathrm{Cu}$, respectively, with the remainder supplied by sulfate forms of these metals. Cobalt glucoheptonate (COPRO; Zinpro Corp.) and EDDI supplied 100\% of the Co and I, respectively. All of the Se was supplied by sodium selenite. The standard trace mineral premix was formulated to provide daily (per $45 \mathrm{~kg}$ of BW) 35 $\mathrm{mg}$ of $\mathrm{Zn}, 37 \mathrm{mg}$ of $\mathrm{Mn}, 12 \mathrm{mg}$ of $\mathrm{Cu}, 0.53 \mathrm{mg}$ of $\mathrm{Co}$, $0.42 \mathrm{mg}$ of I, and $0.32 \mathrm{mg}$ of Se. Sulfates supplied all of the $\mathrm{Mn}$ and $\mathrm{Cu}$, and EDDI, cobalt carbonate, and sodium selenite supplied all the I, Co, and Se, respectively. Zinc was supplied by a combination of Zn sulfate and Zinpro Zn methionine complex (Zinpro Corp.).

Allocation to the interventions was performed by randomly assigned ear tags numbered between 1 and 120. Animals with numbers from 1 to 60 were allocated to the HOTMI premix-fed group and numbers 61 to 120 were allocated to the standard trace mineral mix group. Baseline characteristics after randomization are shown in Table 1. The same base ration was used for both groups and was composed of alfalfa haylage, corn silage, and a mixed concentrate of cereals and macrominerals (Table 2). Diets were formulated to meet or exceed nutrient requirements to support an average daily gain of $0.8 \mathrm{~kg}$, including trace mineral requirements (NRC, 2001). Two evaluations (at d 30 and 60) were made in a stand-up restraint chute to detect possible DD infections naturally acquired on the farm on any of the 4 feet. The timeline of the study is shown in Figure 2a.

Challenge Phase. Fifteen steers free of macroscopic DD lesions were randomly selected from each of the treatment and control groups on d 60 after enrollment and transported to the Livestock Laboratory. The steers were selected from each group by using a random list of numbers generated using Excel software (Microsoft Corp., Redmond, WA).The same diet group allocation was maintained for the $60 \mathrm{~d}$ of the challenge phase. The HOTMI premix was formulated as for the natural exposure phase. The standard trace mineral premix was formulated to provide daily (per $45 \mathrm{~kg}$ of BW) $74 \mathrm{mg}$ of Zn, $65 \mathrm{mg}$ of $\mathrm{Mn}, 15 \mathrm{mg}$ of $\mathrm{Cu}, 1.0 \mathrm{mg}$ of Co, $1.4 \mathrm{mg}$ of I, and $0.42 \mathrm{mg}$ of Se. In contrast to the natural exposure phase of the study, all Zn was supplied by Zn sulfate.

Attempts to induce experimental DD lesions were made according to the Gomez et al. (2012) modifications of the Read and Walker (1998b) infection model. Digital skin of 20 feet in each group was inoculated with a homogenate of DD lesion biopsy material obtained from commercial dairy operations; 10 animals were inoculated in the right rear foot and 5 animals 
Table 1. Baseline characteristics (means, with SD in parentheses) of steers for the natural exposure and challenge phases

\begin{tabular}{lccccc}
\hline & \multicolumn{2}{c}{$\begin{array}{c}\text { Natural exposure phase } \\
(0 \text { to } 60 \mathrm{~d} \text { after enrollment })\end{array}$} & & \multicolumn{2}{c}{$\begin{array}{c}\text { Challenge phase } \\
(60 \text { to } 120 \text { d after enrollment })\end{array}$} \\
\cline { 2 - 3 } \cline { 5 - 6 } Item & $\begin{array}{c}\text { Control group } \\
(\mathrm{n}=60)\end{array}$ & $\begin{array}{c}\text { Treatment group } \\
(\mathrm{n}=60)\end{array}$ & & $\begin{array}{c}\text { Control group } \\
(\mathrm{n}=15)\end{array}$ & $\begin{array}{c}\text { Treatment group } \\
(\mathrm{n}=15)\end{array}$ \\
\hline Age $(\mathrm{mo})$ & $5.9(0.25)$ & $5.8(0.27)$ & & $7.9(0.22)$ & $7.9(0.21)$ \\
Weight $(\mathrm{kg})$ & $194.9(18.2)$ & $194.4(16.6)$ & & $256.8(17.3)$ & $252.5(21.4)$ \\
DD lesions & 0 & 0 & 0 & 0 \\
\hline
\end{tabular}

${ }^{1} \mathrm{DD}=$ digital dermatitis.

were inoculated in both rear feet. The remaining 10 left rear feet were used as sham inoculation. Animals were selected randomly to receive sham inoculations and equivalent inoculation distribution was performed across treatments. Using a stand-up restraint chute, gross visual examination of DD lesions was performed twice per week on all inoculated feet, including sham inoculations, until completion of the study (Figure 2b).

\section{Outcomes}

According to the DD classification described by Döpfer et al. (1997), the primary outcome of the study was defined as an active ulcerative DD lesion $\geq 20 \mathrm{~mm}$ across the largest dimension (an M2 lesion). Digital dermatitis lesions $<20 \mathrm{~mm}$ were classified as M1 lesions. Given that in a single foot several DD lesions might be present, a secondary outcome was defined as the diameter of M1 and M2 lesions present in the foot upon diagnosis of an M2 lesion or the diameter of M1 lesions at d 60 of the challenge phase when only M1 lesions were present. The outcomes were determined by clinical inspection and by measuring the largest dimension of the lesions with a caliper [General Pocket Caliper (132me); General Tools LLC, New York, NY].

\section{Additional Analysis}

To evaluate potential differences in blood and liver trace mineral contents between the groups, blood samples were taken on d 1, 14, and 29 of the challenge phase and upon detection of an acute DD lesion, using a Vacutainer tube (BD reference number 369737; royal blue trace element serum tube; BD, Franklin Lakes, $\mathrm{NJ})$. Within $12 \mathrm{~h}$ of collection, blood was centrifuged at $1,500 \times g$ for $10 \mathrm{~m}$ at room temperature $\left(\sim 23^{\circ} \mathrm{C}\right)$, serum was harvested into microcentrifuge tubes (1.7 $\mathrm{mL}$; VWR International LLC, Radnor, PA) and frozen at $-80^{\circ} \mathrm{C}$ until serum was analyzed for $\mathrm{Co}, \mathrm{Cu}, \mathrm{Fe}, \mathrm{Mn}$, Mo, Zn, Se, and I concentrations (Diagnostic Center for

Table 2. Nutritional composition analysis of the diets fed during the natural exposure and challenge phases

\begin{tabular}{|c|c|c|c|c|}
\hline \multirow{2}{*}{$\begin{array}{l}\text { Nutrient } \\
\text { content }\end{array}$} & \multicolumn{2}{|c|}{ Natural exposure phase } & \multicolumn{2}{|c|}{ Challenge phase } \\
\hline & Control & Treatment & Control & Treatment \\
\hline $\mathrm{NE}_{\mathrm{M}}($ Mcal $/ \mathrm{kg})$ & 1.66 & 1.60 & 1.41 & 1.43 \\
\hline $\mathrm{CP}(\%)$ & 16.09 & 14.28 & 16.72 & 17.34 \\
\hline Fat (\%) & 3.06 & 2.76 & 3.45 & 3.45 \\
\hline Ash (\%) & 6.81 & 6.74 & 8.70 & 8.63 \\
\hline $\operatorname{ADF}(\%)$ & 22.67 & 24.41 & 26.42 & 27.48 \\
\hline NDF $(\%)$ & 37.78 & 41.96 & 40.15 & 39.41 \\
\hline NFC (\%) & 36.27 & 34.26 & 31.81 & 32.03 \\
\hline TDN $(\%)$ & 71.14 & 69.08 & 64.5 & 62.81 \\
\hline $\mathrm{Ca}(\%)$ & 0.99 & 0.83 & 1.15 & 1.16 \\
\hline $\mathrm{P}(\%)$ & 0.34 & 0.34 & 0.43 & 0.42 \\
\hline $\mathrm{Mg}(\%)$ & 0.33 & 0.32 & 0.4 & 0.41 \\
\hline $\mathrm{K}(\%)$ & 1.66 & 1.61 & 2.08 & 2.07 \\
\hline $\mathrm{Na}(\%)$ & 0.18 & 0.13 & 0.28 & 0.27 \\
\hline $\mathrm{Cl}^{-}(\%)$ & 0.44 & 0.62 & 0.87 & 0.89 \\
\hline S (\%) & 0.24 & 0.26 & 0.19 & 0.19 \\
\hline $\operatorname{Mn}(\mathrm{mg} / \mathrm{kg})$ & 42.5 & 115.5 & 119 & 109 \\
\hline $\mathrm{Zn}(\mathrm{mg} / \mathrm{kg})$ & 64 & 161.5 & 103 & 121 \\
\hline $\mathrm{Cu}(\mathrm{mg} / \mathrm{kg})$ & 30 & 37.5 & 23 & 20 \\
\hline $\mathrm{Fe}(\mathrm{mg} / \mathrm{kg})$ & 174.5 & 239 & 246 & 237 \\
\hline Mo (mg/kg) & 0.57 & 0.54 & 0.87 & 0.85 \\
\hline
\end{tabular}


(a)

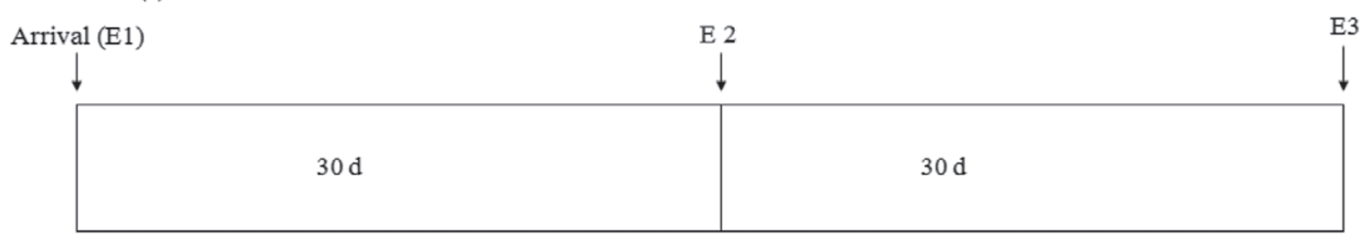

(b)

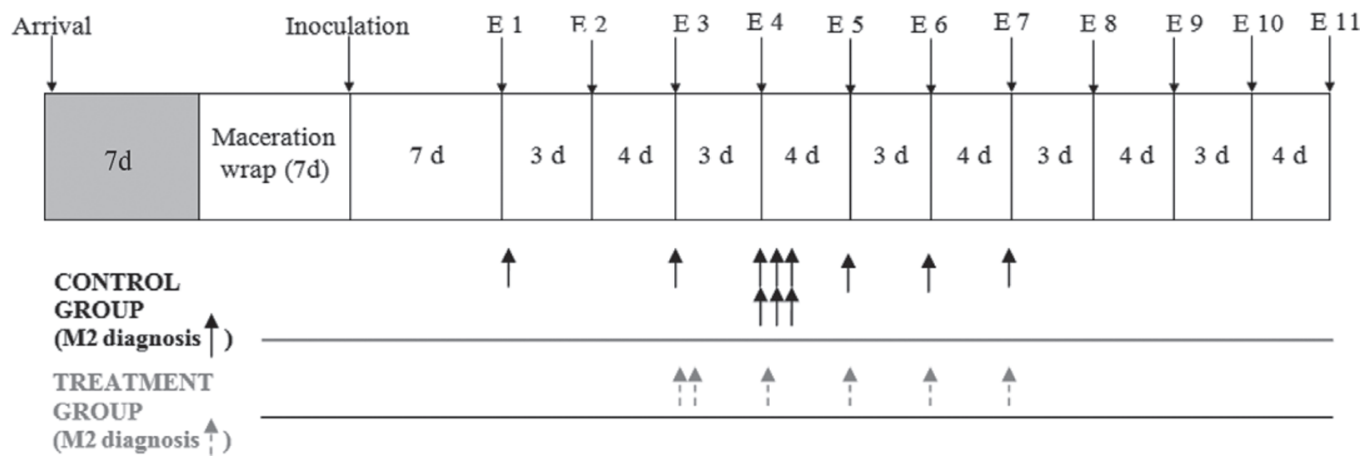

Figure 2. Timeline of the natural exposure (a) and challenge (b) phases, showing maceration wrap and inoculation periods, evaluation number $(\mathrm{E})$, interval days (d) between events, and digital dermatitis (DD) diagnosis (arrows). M2 = ulcerative DD lesion $>20$ mm across the largest dimension.

Population and Animal Health, Michigan State University, Lansing). Liver biopsies were taken upon detection of an acute DD lesion or on d 60 of the challenge phase for animals without M2 diagnosis. Liver biopsies were performed as described in Corah and Arthington (1995) using a True-Cut biopsy instrument (Baxter Healthcare, Valencia, CA), stored in a trace elements serum tube (BD reference number 369737; royal blue trace elements serum tube; BD) and analyzed on a DM basis for $\mathrm{Co}, \mathrm{Cu}, \mathrm{Fe}, \mathrm{Mn}, \mathrm{Mo}, \mathrm{Zn}$, and Se concentrations (Diagnostic Center for Population and Animal Health, Michigan State University).

After clinical identification of a lesion compatible with M2 DD, a full-skin thickness punch biopsy was taken, following the procedure reported in Gomez et al. (2012), and inspected for motile spirochetes using a wet mount of a drop of ground biopsy in culture medium under a dark-field microscope at 200× (80i; Nikon, Milwaukee, WI). Polymerase chain reaction was used to test for the presence of Treponema-like microorganisms in all samples, including sham inoculations (Evans et al., 2008). A second biopsy of the same lesion was placed in $10 \%$ neutral buffered formalin and submitted for histopathologic evaluation by one of the authors (D. H. Read). Tissues were processed routinely to wax; sectioned at $5 \mu \mathrm{m}$; stained by hematoxylin-eosin, MayGrünwald-Giemsa, and modified Steiner silver staining; and subjected to an immunohistochemical (IHC) procedure using a polyclonal antiserum to a PDD/DDassociated Treponema spp. [Walker isolate 1-9185MED, phenotype group 1, phylotype group 1, most closely resembling (mcr) Treponema denticola; Walker et al., 1995]. Twelve additional control biopsies were taken from equivalent dewclaw areas in sham feet, without biopsy homogenate inoculation, to evaluate possible cross-contamination. Histopathologic diagnosis of DD and classification was blind to clinical classification and made according to the guidelines prescribed by Berry et al. (2010). A diagnosis of DD was made if the following was observed: loss of stratum corneum, invasion of eroded and hyperplastic epidermis and ulcerated papillary dermis by spirochete-dominant bacterial flora, and reactive inflammation. Steiner silver stain was used to detect spirochetes and the IHC procedure was used to determine if the spirochetes were antigenically related to PDD/DD-associated Treponema sp. (mcr) T. denticola. After M2 diagnosis or biopsy, and cleaning using a disposable towel, the lesions were treated topically in the stand-up restraint chute using liquid oxytetracycline (Oxy-Mycin 100 mg/mL; Agripharm Products, West Lake, TX) under a light wrap (Coban; 3M, Saint Paul, MN), which was removed in $24 \mathrm{~h}$.

\section{Blinding}

The staff responsible for the feeding of the animals, and the evaluator of the histopathology samples were blinded to treatment allocation. However, the investigator and 2 technicians were aware of the group allocation. 


\section{Sample Size and Statistical Analysis}

To detect a reduction in the total incidence of M2 infections of $50 \%$ during the challenge phase with a type I error of $5 \%$, a type II error of $20 \%$, and a predicted incidence of experimentally induced lesions of 95\%, 15 steers were randomized to each group. The sample size estimate accounted for $10 \%$ possible losses to follow-up due to health issues or unexpected adverse events.

Logistic regression was used to analyze the presence of an M2 DD lesion, with the foot being the unit of observation (primary outcome). The nesting characteristic of both rear feet on the same steer was considered as a random term in the regression model. A linear mixed regression model was used to evaluate the lesion size as a secondary outcome as indicated in Equation 1:

$$
\begin{aligned}
& \text { Lesion size }_{i j} \sim \beta_{0}+\beta_{1} \text { DD lesion type } \\
& +\beta_{2} \text { Treatment group }_{i j}+\beta_{3} \text { DD lesion type } \\
& \text { (j }
\end{aligned}
$$

where $j=j$ th lesion in a foot, $i=i$ th steer unique identifier, $\beta_{0}=$ intercept, $\beta_{1}=$ estimate of the mean lesion size difference between treatment and control groups, $\beta_{2}=$ estimate of the mean M1 DD lesion size, $\beta_{3}=$ estimation of the difference in M2 lesion size between the control and treatment groups, $\nu_{i}=$ random steer term, and $\varepsilon_{j}=$ residual error. Lesion size $=$ millimeters across the largest dimension of the lesion, DD lesion type $=\mathrm{M} 1$ or M2 DD, Treatment group = treatment or control group (reference), DD lesion type ${ }_{i j} \times$ Treatment group $=$ interaction term between lesion type and treatment group. Similarly, a random term was included in the model to account for the nesting of both rear feet in the same animal and diagnostic plots were checked to assess the assumption about constant variance of the residuals and potential linear trends. The $\mathrm{R}$ software (R Core Team, 2013) was used to perform the statistical analysis.

\section{RESULTS}

\section{Primary and Secondary Outcomes}

During the natural exposure phase, no DD infections were diagnosed. Therefore, the evaluation of the nutritional supplement effect under natural conditions was inconclusive.

A summary of the challenge phase results are shown in Tables 3 and 4 for the primary and secondary outcomes, respectively. Fifty-five and $30 \%$ of feet with an M2-stage DD lesion were diagnosed in the control and treatment groups, respectively. The median (95\% CI) time to diagnosis was 28 (22 to 34$)$ and 32 (30 to 40) d in the control and treatment groups, respectively $(P=$ 0.11 ; Figure 3 ). The level of M1 DD observed was found equivalent between the groups up to d 10 postinoculation. An M1 DD infection was identified in 70\% (14/20) and $60 \%(12 / 20)$ of feet in the treatment and control groups, respectively. During the study and without topical antibiotic intervention, M1 lesions evolved either to an M2 lesion, maintained the M1 status until the termination of the study, or healed with total restoration of the skin.

When M1 and M2 lesions were considered, similar M1 lesion size was found in the treatment group (7.23 $\mathrm{mm} ; \mathrm{SE}=0.75 \mathrm{~mm})$ versus the control group (7.35 $\mathrm{mm} ; \mathrm{SE}=0.75 \mathrm{~mm}$; Figure 4). However, larger M2 lesions were observed at diagnosis in the control group (mean $=27.58 \mathrm{~mm} ; \mathrm{SE}=2.13 \mathrm{~mm}$ ) compared with the treatment group $($ mean $=23.85 \mathrm{~mm} ; \mathrm{SE}=1.65 \mathrm{~mm})$. Although the adjusted difference of $-4.15 \mathrm{~mm}$ observed in the treatment group was not found to be statistically significantly different from the control group $(P=$ 0.11 ), it demonstrated a beneficial trend resulting from feeding the HOTMI premix (Table 4).

\section{Serum and Liver Mineral Content}

During the challenge phase, significant differences in liver Co and Se, and serum Co and I concentrations

\begin{tabular}{|c|c|c|c|c|}
\hline \multirow[b]{2}{*}{ Primary outcome } & \multicolumn{2}{|c|}{ Percentage (no. of feet) } & \multirow[b]{2}{*}{$\begin{array}{c}\text { Risk ratio }^{1} \\
(95 \% \mathrm{CI})\end{array}$} & \multirow[b]{2}{*}{$\begin{array}{c}\text { Risk difference } \\
\quad \%(95 \% \text { CI })\end{array}$} \\
\hline & $\begin{array}{c}\text { Control } \\
\text { supplement } \\
(\mathrm{n}=20)\end{array}$ & $\begin{array}{l}\text { Treatment } \\
\text { supplement } \\
(\mathrm{n}=20)\end{array}$ & & \\
\hline $\begin{array}{l}\text { Proportion of feet developing an M2 } \\
\text { DD infection }\end{array}$ & $55(11)$ & $30(6)$ & $0.54^{*}(0.18$ to 1.09$)$ & $-25(-49.6$ to 5$)$ \\
\hline
\end{tabular}

Table 3. Absolute and relative risk of developing an infection with an active ulcerative digital dermatitis (DD) lesion $\geq 20 \mathrm{~mm}$ across the largest dimension (M2 DD) during the challenge phase 
Table 4. Summary of the estimation of the digital dermatitis (DD) lesion size differences observed between the treatment and control groups considering DD stages with lesions $<20 \mathrm{~mm}$ (M1) and active ulcerative DD lesions $>20 \mathrm{~mm}$ across the largest dimension (M2)

\begin{tabular}{lcccc}
\hline & \multicolumn{4}{c}{ Secondary outcome: DD lesion size } \\
\cline { 2 - 5 } Item & Mean & $\mathrm{SE}$ & $95 \%$ CI & $P$-value \\
\hline Intercept (control) & 7.57 & 1.23 & 5.24 to 9.70 & 0.98 \\
Treatment & -0.03 & 1.56 & -3.03 to 2.81 & $<0.01$ \\
M1 stage & Reference & - & - & -16.6 to 23.4 \\
M2 stage & 19.96 & 1.7 & -8.89 to 1.54 & 0.11 \\
Treatment $\times$ M2 stage & -4.15 & 2.6 &
\end{tabular}

were observed between the treatment groups (Table 5). Furthermore, liver concentrations of $\mathrm{Co}, \mathrm{Mn}$, and Se in the control group and liver concentrations of Co and $\mathrm{Cu}$ in the treatment group were significantly lower in animals diagnosed with an M2 lesion (Table 6).

\section{Histopathology and Direct Observation}

All lesions diagnosed clinically as M2 stage of DD were confirmed histopathologically as DD. Spirochetes were consistently detected by dark-field microscopy in all biopsies collected from M2 lesions. Histopathologically, Steiner silver stain consistently detected invasive spirochetes in stratum spinosum and papillary dermis, and the IHC procedure consistently demonstrated that the spirochetes were antigenically related to PDD/ DD-associated Treponema spp. in all M2 lesions. The presence of Treponema spp. organisms were confirmed

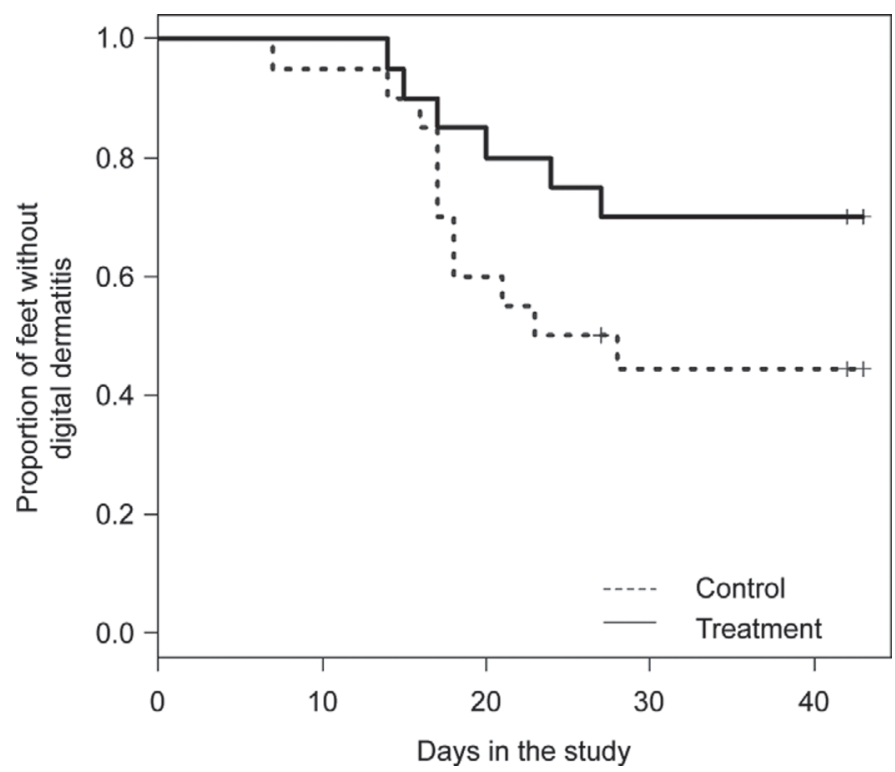

Figure 3. Survival curve of digital dermatitis (DD) diagnosis involving an active ulcerative DD lesion $>20 \mathrm{~mm}$ across the largest dimension (M2 DD) during the challenge phase of the study. $+=$ censored observations. by PCR. Spirochetes were not identified in any biopsies from comparable locations in sham inoculation feet (n $=12$ ) by any of the staining techniques.

\section{DISCUSSION}

This study compared the effect of feeding HOTMI premix versus a standard trace mineral premix on incidence and size of DD lesions in Holstein steers under natural and experimental infection settings. No DD lesions were observed during the natural exposure phase and, therefore, comparison between HOTMI and standard trace minerals could not be made. However, for experimentally induced lesions, the results showed a decreased number of M2 lesions in the HOTMI group (30 vs. $55 \%$ of feet diagnosed in the control group), as well as decreased size of M2 lesions [23.85 $\mathrm{mm}$ ( $\mathrm{SE}=$ $1.65 \mathrm{~mm})$ vs. $27.58 \mathrm{~mm}(\mathrm{SE}=2.13 \mathrm{~mm})$ in the control group], suggesting a beneficial effect of the HOTMI premix in preventing DD lesions. However, none of these

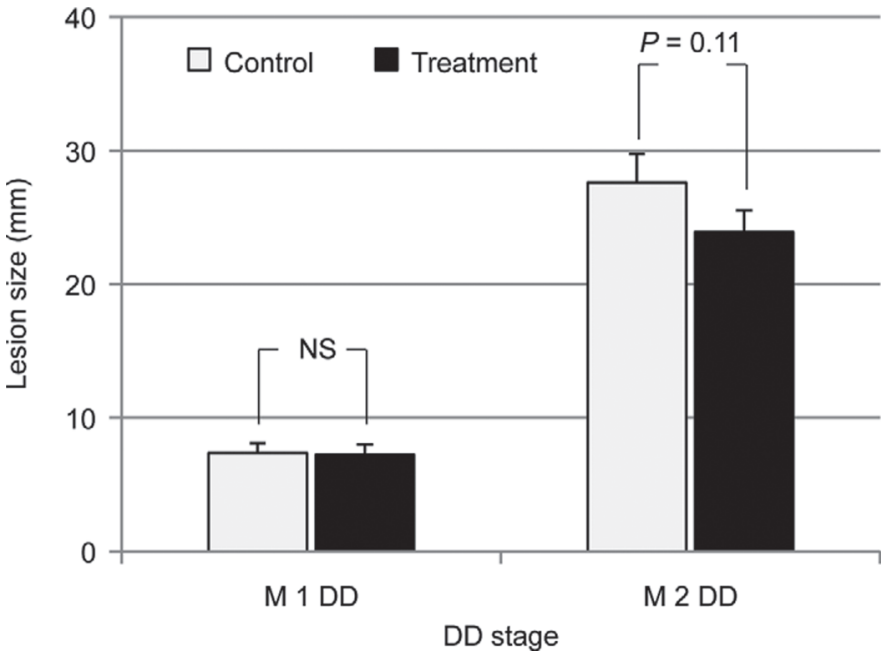

Figure 4. Final mean (with SEM) digital dermatitis (DD) lesion sizes for lesions $<20 \mathrm{~mm}$ (M1) and active ulcerative DD lesions $\geq 20$ $\mathrm{mm}$ across the largest dimension (M2) observed during the challenge phase of the study in treatment and control groups, and statistical significance of the difference evaluation. 
Table 5. Mean (SEM) serum trace mineral content from samples taken on d 1, 14, and 29 of the challenge phase and liver trace mineral content upon diagnosis of an active ulcerative digital dermatitis (DD) lesion $>20 \mathrm{~mm}$ across the largest dimension (M2) or termination of the study

\begin{tabular}{|c|c|c|c|c|c|c|c|c|}
\hline \multirow[b]{2}{*}{ Micromineral } & \multicolumn{4}{|c|}{ Serum analysis } & \multicolumn{4}{|c|}{ Liver analysis } \\
\hline & Units & Control & Treatment & $P$-value & Units & Control & Treatment & $P$-value \\
\hline $\mathrm{Cu}$ & $\mu \mathrm{g} / \mathrm{mL}$ & $0.76(0.02)$ & $0.72(0.03)$ & 0.59 & $\mu \mathrm{g} / \mathrm{g}$ & $514.4(44.45)$ & $519.7(62.87)$ & 0.81 \\
\hline $\mathrm{Fe}$ & $\mu \mathrm{g} / \mathrm{dL}$ & $125.4(5.99)$ & $131.6(8.52)$ & 0.56 & $\mu \mathrm{g} / \mathrm{g}$ & $226.8(15.13)$ & $253.1(21.40)$ & 0.23 \\
\hline $\mathrm{Mn}$ & $\mathrm{ng} / \mathrm{mL}$ & $1.31(0.17)$ & $1.53(0.24)$ & 0.11 & $\mu \mathrm{g} / \mathrm{g}$ & $9.86(0.48)$ & $10.0(0.68)$ & 0.83 \\
\hline Mo & $\mathrm{ng} / \mathrm{mL}$ & $43.0(5.85)$ & $51.1(8.3)$ & 0.32 & $\mu \mathrm{g} / \mathrm{g}$ & $3.84(0.23)$ & $3.86(0.32)$ & 0.95 \\
\hline I & $\mathrm{ng} / \mathrm{mL}$ & $107.5(7.62)$ & $248.4(10.8)$ & $<0.001^{* *}$ & & & & \\
\hline
\end{tabular}

$* * P<0.05$.

differences were statistically significant $(P=0.11$; Table 3). The original sample size calculation was conditional on an infection rate of $95 \%$ in the control group and a proposed relative reduction in active DD in the HOTMI premix group of $50 \%$ and none of these thresholds were achieved. The final number of steers included in the study corresponded to a power of $60 \%$ and this was not sufficient to demonstrate the $45 \%$ difference achieved at a significance level of $5 \%$. Future trials using the current DD experimental infection model should take into account the incidence of infection achieved in the present study to calculate appropriate sample sizes and achieve adequate power.

It is difficult to determine whether the response was the result of providing an increased supply of one mineral or a combination of minerals. Significant differences in the levels of some blood and liver trace minerals were found between treatment and control groups. Iodine may have an important role in the beneficial effects of the HOTMI premix on incidence and severity of DD lesions, as the group being fed HOTMI premix had higher serum I levels $(P<0.01)$ than the control group. Iodine in the form of EDDI, included in the HOTMI premix, has been used previously in bovine skin-related disease prevention (Çam et al., 2007).
Ethylenediamine dihydroiodide has been shown to be efficacious in preventing experimentally induced bovine foot rot using mouse and cow models (Berg et al., 1984). Currently, Food and Drug Administration regulations limit the use of EDDI to $49.9 \mathrm{mg} /$ animal per day (Food and Drug Administration Office of Regulatory Affairs, Compliance Policy Guide for EDDI; CPG Sec. 651.100, 2000). Furthermore, if milk iodine concentrations are excessive, the milk is considered adulterated and the dairy producer is liable. Therefore, the HOTMI premix fed in this study should be restricted to nonlactating animals. Steers in the HOTMI group consumed greater amounts of some trace minerals (i.e., $29 \mathrm{mg}$ of $\mathrm{Zn}$ and $2.6 \mathrm{mg}$ of I per $45 \mathrm{~kg}$ of BW more were consumed by the HOTMI group, respectively, than by the control group) and, therefore, environmental accumulation of heavy metals by the elevated mineral ingestion could be a concern (López-Alonso, 2012); diets were specifically formulated below the dietary maximum allowance of mineral levels in livestock production.

The HOTMI premix group had lower concentrations of Se in the liver and higher Co concentrations in both serum and liver compared with the control group (Table $5)$. The higher liver Se concentrations for the control group may be due, in part, to the control heifers being

Table 6. Liver trace mineral content (means, with SD in parentheses) observed based on diagnosis of an active ulcerative digital dermatitis (DD) lesion $\geq 20 \mathrm{~mm}$ across the largest dimension (M2 DD) and intervention group

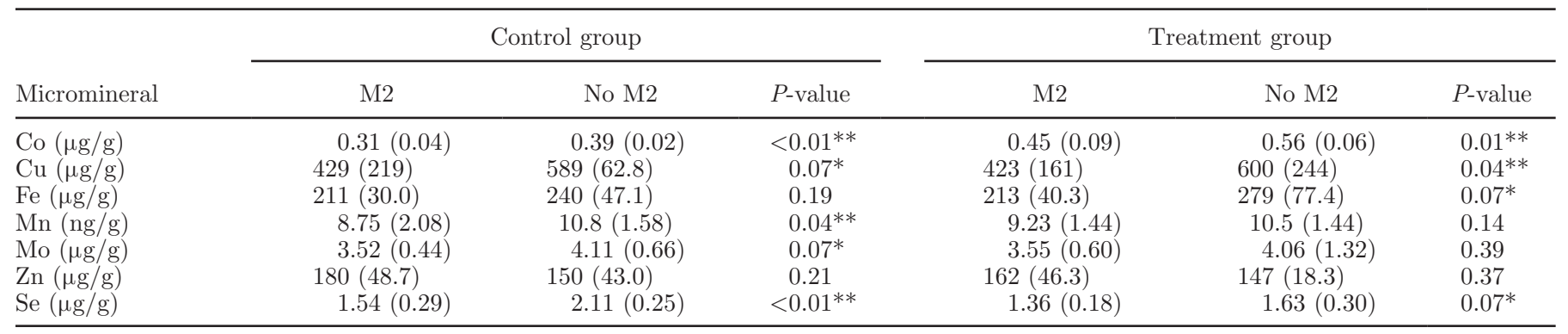

$* P<0.1 ;{ }^{* *} P<0.05$. 
fed more Se per unit of BW during the challenge phase of the study. The higher serum and liver Co concentrations may be due, in part, to steers fed the HOTMI premix consuming approximately twice as much Co during the natural exposure phase. However, during the challenge phase of the study, both groups of steers received approximately the same amount of Co per unit of BW (1.1 and $1.0 \mathrm{mg}$ of $\mathrm{Co}$ per $45 \mathrm{~kg}$ of $\mathrm{BW}$ for HOTMI and control premixes, respectively). Another possible explanation for steers fed the HOTMI premix having higher serum and liver Co concentrations than control steers was that they were fed Co in the form of Co glucoheptonate, whereas control steers were fed Co in the form of Co carbonate. Akins et al. (2013) found no difference in liver Co concentrations when dairy cattle received $25 \mathrm{mg}$ of Co from either feed-grade Co carbonate or feed-grade Co glucoheptonate from $60 \mathrm{~d}$ prepartum through $150 \mathrm{~d}$ postpartum. For both the treatment and HOTMI steers, liver Co concentrations were lower when steers were diagnosed with an M2 lesion (Table 6). It is not certain whether having lower liver Co concentrations predisposed steers to M2 lesions or whether the development of an M2 lesion resulted in lower Co concentrations in the liver. Cobalt is primarily utilized by rumen microbes for the formation vitamin $\mathrm{B}_{12}$ and may also aid in fiber digestion (NRC, 2001). No known function exists for Co once absorbed and it does not appear to be recycled back to the rumen after absorption (NRC, 2001). Thus, we know of no potential mode of action for increased Co status increasing the ability of the animal to resist M2 lesions.

When compared with the control premix, the HOTMI premix provided animals with approximately 1.6 times more $\mathrm{Zn}$ and 2.9 times more I. In addition, all the $\mathrm{Zn}, \mathrm{Mn}, \mathrm{Cu}$, and $\mathrm{Co}$ in the control premix was supplied by inorganic minerals, whereas in the HOTMI premix, a portion of the $\mathrm{Zn}, \mathrm{Mn}$, and $\mathrm{Cu}$ were supplied by amino acid complexes.

Association of organic compounds, mainly amino acids, with trace minerals has previously been shown to increase their bioavailability (Wedekind et al., 1992; Spears, 1996). This could explain differences in the performance of diets including OTM against diets based on inorganic sources of trace minerals (Nocek et al., 2006; Siciliano-Jones et al., 2008; DeFrain et al., 2009).

However, no differences were found between the treatment and control groups in Zn serum and liver concentrations. Given that several tissues, such as bones, are responsible for the retention and release of $\mathrm{Zn}$, influencing plasma turnover of $\mathrm{Zn}$, blood and liver Zn levels are considered poor indicators of Zn bioavailability (Kincaid, 1999). However, the role of increased $\mathrm{Zn}$ supply in reducing the severity and size of DD lesions cannot be dismissed, given its role in immune function, specifically modulating IL-8 (Zhao et al., 2011). Interleukin 8 has been correlated with keratinocyte activity in DD pathogenesis (Refaai et al., 2013). Manganese may also have a role in the responses observed when the HOTMI premix was fed. First, liver Mn concentrations were lower $(P<0.05)$ in animals diagnosed with M2 lesions. Second, a trend $(P<0.11)$ existed for serum Mn to be higher in HOTMI steers compared with control steers. The role of $\mathrm{Mn}$ in the positive response to the HOTMI premix may be related to its role as an antioxidant, with implications for wound healing and immune cell function (Keen and Zidenberg-Cherr, 1996; Muszyńska et al., 2000; Son et al., 2007).

As previously noted, in steers with M2 lesions, several trace minerals were significantly decreased relative to steers without M2 lesions (Table 6). This suggests that during a DD infection, some trace minerals are more rapidly consumed, have elevated metabolism, or protect or solve DD infection. However, the exact role of trace minerals during DD infection remains speculative, as no previous research is available to support it. Alternatively, the potential decrease in feed intake due to pain and discomfort as a consequence of DD lesions might have modified the trace mineral levels observed in DD-affected animals (Bareille et al. 2003), although this seems less plausible, given that no signs of lameness or changes in behavior were observed during the trial.

Current nutritional recommendations by NRC (2001) are calculated for animals without special healthrelated needs, such as stress or presence of antagonists. Therefore, trace mineral dietary recommendations are formulated for normal situations. But there is a lack of knowledge regarding trace mineral needs of livestock during periods of disease and how blood and liver trace mineral concentrations are modified within the normal range during situations of increased need. In critically ill human patients, however, increased trace mineral requirements are well documented to be related to disease processes (Berger et al., 2007; Heyland et al., 2008; Doley, 2010). Discussions regarding trace mineral profiles need to take into consideration the dependency of the trace mineral content on dietary availability of minerals and the variation of the reference values used by different laboratories or literature sources (Puls, 1994; Herdt and Hoff, 2011).

Specifically for animals, strong evidence exists to support an association between cellular immune response, skin health, and wound healing with adequate nutritional plane and bioavailability of trace minerals (Tenaud et al., 2000; Richelle et al., 2006; Kharaeva et al., 2009). This can be particularly important in situations where the skin health is compromised by external 
stressors (Tomlinson et al., 2004). During the challenge phase of the current study, the hind feet were subjected to continuous moisture (maceration) and reduced access to air (closure) by the wrapping procedure. Changes in the skin were evident throughout the study, manifesting themselves as marked skin maceration in all wrapped feet. Other skin infections, such as ulcerative mammary dermatitis (Evans et al., 2010) or ringworm (Çam et al., 2007), may also benefit from this type of nutritional supplementation.

The final level of DD incidence induced using the infection model in this study $(55 \%)$ is encouraging to recommend this approach as a gold standard for investigation into the efficacy of DD intervention strategies. This is particularly true if future studies take this incidence into account and adjust power calculations accordingly. Of particular importance is the ability of this experimental infection model to eliminate many of the confounding factors prevalent in field studies (Wells et al., 1999; Berry et al., 2002; Teixeira et al., 2010) that may contribute to inconclusive results. In addition, Treponema-like organisms were not identified in any of the samples collected from equivalent dewclaw areas in sham inoculations, confirming successful isolation of the experimentally induced lesions from the surrounding environment and from possible cross-contamination during the numerous feet manipulations.

In addition to the previously discussed lack of power, another limitation of the study was the possible introduction of observer bias in the evaluation of the DD lesions. The principal author and 2 technicians, all of whom were aware of the treatment allocation, were responsible for diagnosis of the DD lesions. However, clinical DD diagnosis is simple in the experimental setting, and photographs of the lesions and measurements were recorded for later reassessment, if needed.

\section{CONCLUSIONS}

Although more research is needed to confirm the results observed in the present study, the trend of decreased DD incidence and decreased lesion size is suggestive that the HOTMI premix could be a novel strategy for controlling DD in the field. This control strategy could focus on high-risk groups such as beef cattle, dairy heifers, and transition cows before parturition. Additionally, the bovine DD infection model appears to be adequate to evaluate the efficacy of intervention strategies aimed at controlling DD, with the advantage of decreasing the number of confounding factors often encountered in field trials and minimizing the number of animals needed to demonstrate efficacy.

\section{ACKNOWLEDGMENTS}

This study was supported by Zinpro Corp. (Eden Prairie, MN). The authors thank Karl Burgi (Comfort Hoof Care Inc., Baraboo, WI) and the farmers involved in the study for their time and patience.

\section{REFERENCES}

Akins, M. S., S. J. Bertics, M. T. Socha, and R. D. Shaver. 2013. Effects of cobalt supplementation and vitamin $\mathrm{B}_{12}$ injections on lactation performance and metabolism of Holstein dairy cows. J. Dairy Sci. 96:1755-1768.

Bareille, N., F. Beaudeau, S. Billon, A. Robert, and P. Faverdin. 2003. Effects of health disorders on feed intake and milk production in dairy cows. Livest. Prod. Sci. 83:53-62.

Berg, J. N., J. P. Maas, J. A. Paterson, G. F. Krause, and L. E. Davis. 1984. Efficacy of ethylenediamine dihydriodide as an agent to prevent experimentally induced bovine foot rot. Am. J. Vet. Res. 45:1073-1078.

Berger, M. M., C. Binnert, R. L. Chiolero, W. Taylor, W. Raffoul, M.C. Cayeux, M. Benathan, A. Shenkin, and L. Tappy. 2007. Trace element supplementation after major burns increases burned skin trace element concentrations and modulates local protein metabolism but not whole-body substrate metabolism. Am. J. Clin. Nutr. 85:1301-1306.

Berry, S. L., D. H. Read, R. L. Walker, and T. R. Famula. 2010. Clinical, histologic, and bacteriologic findings in dairy cows with digital dermatitis (footwarts) one month after topical treatment with lincomycin hydrochloride or oxytetracycline hydrochloride. J. Am. Vet. Med. Assoc. 237:555-560.

Berry, S. L., D. H. Read, R. L. Walker, and D. W. Hird. 2002. Etiology, treatment and prospects for vaccination against (papillomatous) digital dermatitis. Pages 5-11 in Proc. Int. Symp. Lameness Rumin., Orlando, FL. J. K. Sharer, ed.

Blowey, R. W., and M. W. Sharp. 1988. Digital dermatitis in dairy cattle. Vet. Rec. 122:505-508.

Bruijnis, M. R. N., H. Hogeveen, and E. N. Stassen. 2010. Assessing economic consequences of foot disorders in dairy cattle using a dynamic stochastic simulation model. J. Dairy Sci. 93:2419-2432.

Çam, Y., K. S. Gümüssoy, M. Kibar, N. Apaydin, and Ö. Atalay. 2007. Efficacy of ethylenediamine dihydriodide for the treatment of ringworm in young cattle. Vet. Rec. 160:408-410.

Capion, N., S. M. Thamsborg, and C. Enevoldsen. 2009. Prevalence and severity of foot lesions in Danish Holstein heifers through first lactation. Vet. J. 182:50-58.

Cha, E., J. A. Hertl, D. Bar, and Y. T. Gröhn. 2010. The cost of different types of lameness in dairy cows calculated by dynamic programming. Prev. Vet. Med. 97:1-8.

Corah, L. R., and J. Arthington. 1995. Determining the trace mineral status of a beef cow herd. Agri-Pract. 16:11-14.

DeFrain, J. M., M. T. Socha, D. J. Tomlinson, and D. Kluth. 2009 Effect of complexed trace minerals on the performance of lactating dairy cows on a commercial dairy. Prof. Anim. Sci. 25:709-715.

Doley, J. 2010. Nutrition management of pressure ulcers. Nutr. Clin. Pract. 25:50-60.

Döpfer, D., A. Koopmans, F. A. Meijer, I. Szakáll, Y. H. Schukken, W. Klee, R. B. Bosma, J. L. Cornelisse, A. J. van Asten, and A. A. ter Huurne. 1997. Histological and bacteriological evaluation of digital dermatitis in cattle, with special reference to spirochaetes and Campylobacter faecalis. Vet. Rec. 140:620-623.

Dreher, M., D. Döpfer, T. Mumba, K. Ames, P. Sears, M. Wadell, C. Zwaagstra, and M. Plas. 1999. Clinical effect of local antibiotic treatment of digital dermatitis lesions and detection of spirochetes by means of PCR. Pages 250-251 in Proc. Am. Assoc. Bov. Pract., Nashville, TN. VM Publishing, Stillwater, OK. 
Ettema, J., S. Østergaard, and A. R. Kristensen. 2010. Modelling the economic impact of three lameness causing diseases using herd and cow level evidence. Prev. Vet. Med. 95:64-73.

Evans, N. J., J. M. Brown, I. Demirkan, R. D. Murray, W. D. Vink, R. W. Blowey, C. A. Hart, and S. D. Carter. 2008. Three unique groups of spirochetes isolated from digital dermatitis lesions in UK cattle. Vet. Microbiol. 130:141-150.

Evans, N. J., D. Timofte, S. D. Carter, J. M. Brown, R. Scholey, D. H. Read, and R. W. Blowey. 2010. Association of treponemes with bovine ulcerative mammary dermatitis. Vet. Rec. 166:532-533.

Gengelbach, G. P., J. D. Ward, J. W. Spears, and T. T. Brown Jr. 1997. Effects of copper deficiency and copper deficiency coupled with high dietary iron or molybdenum on phagocytic cell function and response of calves to a respiratory disease challenge. J. Anim. Sci. 75:1112-1118.

Gomez, A., N. B. Cook, N. D. Bernardoni, J. Rieman, A. F. Dusick, R. Hartshorn, M. T. Socha, D. H. Read, and D. Döpfer. 2012. An experimental infection model to induce digital dermatitis infection in cattle. J. Dairy Sci. 95:1821-1830.

Herdt, T. H., and B. Hoff. 2011. The use of blood analysis to evaluate trace mineral status in ruminant livestock. Vet. Clin. North Am. Food Anim. Pract. 27:255-283.

Heyland, D. K., N. Jones, N. Z. Cvijanovich, and H. Wong. 2008. Zinc supplementation in critically ill patients: A key pharmaconutrient? JPEN J. Parenter. Enter. Nutr. 32:509-519.

Holzhauer, M., B. Brummelman, K. Frankena, and T. J. G. M. Lam. 2012. A longitudinal study into the effect of grazing on claw disorders in female calves and young dairy cows. Vet. J. 193:633-638.

Holzhauer, M., D. Döpfer, J. De Boer, and G. Van Schaik. 2008. Effects of different intervention strategies on the incidence of papillomatous digital dermatitis in dairy cows. Vet. Rec. 162:41-46.

Holzhauer, M., C. Hardenberg, C. J. M. Bartels, and K. Frankena. 2006. Herd- and cow-level prevalence of digital dermatitis in the Netherlands and associated factors. J. Dairy Sci. 89:580-588.

Ibs, K.-H., and L. Rink. 2003. Zinc-altered immune function. J. Nutr. $133: 1452 \mathrm{~S}-1456 \mathrm{~S}$

Jorritsma, R., B. J. G. Lansink, and D. Döpfer. 2007. Comparison of the effects of two walk-through footbaths on the prevalence of digital dermatitis and interdigital dermatitis on a commercial dairy farm. Tijdschr. Diergeneeskd. 132:949-952.

Keen, C. L., and S. Zidenberg-Cherr. 1996. Manganese. Pages 334-343 in Present Knowledge in Nutrition. 7th ed. E. E. Ziegler and L. J. Filer, ed. ILSI Press, Washington, DC.

Kharaeva, Z., E. Gostova, C. De Luca, D. Raskovic, and L. Korkina. 2009. Clinical and biochemical effects of coenzyme $\mathrm{Q}_{10}$, vitamin $\mathrm{E}$, and selenium supplementation to psoriasis patients. Nutrition $25: 295-302$.

Kincaid, R. L. 1999. Assessment of trace mineral status of ruminants: A review. Pages 1-8 in Proc. Am. Soc. Anim. Sci. Accessed Apr. 2 , 2014. http://www.fourseasonco.com.au/infosheets/trace_mineral_20120626.pdf.

Klebanoff, S. J., and R. A. Clark. 1978. The Neutrophil: Function and Clinical Disorders. Elsevier/North-Holland Biomedical Press, Amsterdam, the Netherlands.

Laven, R. A., and D. N. Logue. 2007. The effect of pre-calving environment on the development of digital dermatitis in first lactation heifers. Vet. J. 174:310-315.

López-Alonso, M. 2012. Trace minerals and livestock: Not too much not too little. ISRN Vet. Sci. 2012:704825.

Loureiro, M. G., C. A. Rodrigues, E. S. Nascimento, C. Esteban, S. H. Perri, and C. R. Anhesini. 2010. Efficacy of topical and systemic treatments with oxytetracycline for papillomatous digital dermatitis in cows. Arq. Bras. Med. Vet. Zootec. 62:13-22.

Miller, J. K., N. Ramsey, and F. C. Madsen. 1988. The trace minerals. Pages 342-400 in The Ruminant Animal. D. C. Church, ed. Prentice Hall, Englewood Cliffs, NJ.

Moynahan, E. J. 1981. Acrodermatitis enteropathica and the immunological role of zinc. Pages 437-447 in Immunodermatology. B. Safai and R. A. Good, ed. Plenum Medical Book Co., New York, NY.

Muszyńska, A., J. Pałka, and E. Gorodkiewicz. 2000. The mechanism of daunorubicin-induced inhibition of prolidase activity in human skin fibroblasts and its implication to impaired collagen biosynthesis. Exp. Toxicol. Pathol. 52:149-155.

Nocek, J. E., M. T. Socha, and D. J. Tomlinson. 2006. The effect of trace mineral fortification level and source on performance of dairy cattle. J. Dairy Sci. 89:2679-2693.

NRC. 2001. Nutrient Requirements of Dairy Cattle. 7th rev. ed. Natl. Acad. Press, Washington, DC.

Pinna, K., D. S. Kelley, P. C. Taylor, and J. C. King. 2002. Immune functions are maintained in healthy men with low zinc intake. J. Nutr. 132:2033-2036.

Prohaska, J. R., and M. L. Failla. 1993. Copper and immunity. Pages 309-332 in Human Nutrition-A Comprehensive Treatise. Vol. 8. Plenum Press, New York, NY.

Puls, R. 1994. Mineral Levels in Animal Health. 2nd ed. Pages 147 149. Sherpa International, Clearbrook, BC, Canada.

R Core Team. 2013. R: A language and environment for statistical computing. R Foundation for Statistical Computing, Vienna, Austria.

Read, D. H., and R. L. Walker. 1998a. Papillomatous digital dermatitis (footwarts) in California dairy cattle: Clinical and gross pathologic findings. J. Vet. Diagn. Invest. 10:67-76.

Read, D. H., R. W. Nordhausen, and C. J. Walker. 1998. Pathogenesis of experimental papillomatous digital dermatitis (footwarts) in cattle: Bacterial morphotypes associated with early lesion development. Page 271 in Proc. Int. Symp. Lameness Rumin. Lucerne, Switzerland. University of Zurich, Zurich, Switzerland.

Read, D. H., and R. L. Walker. 1998b. Experimental transmission of papillomatous digital dermatitis (footwarts) in dairy cattle. Page 270 in Proc. Int. Symp. Lameness Rumin. Luzerne, Switzerland.

Refaai, W., R. Ducatelle, P. Geldhof, B. Mihi, M. El-shair, and G. Opsomer. 2013. Digital dermatitis in cattle is associated with an excessive innate immune response triggered by the keratinocytes. BMC Vet. Res. 9:193.

Relun, A., A. Lehebel, M. Bruggink, N. Bareille, and R. Guatteo. 2013. Estimation of the relative impact of treatment and herd management practices on prevention of digital dermatitis in French dairy herds. Prev. Vet. Med. 110:558-562.

Richelle, M., M. Sabatier, H. Steiling, and G. Williamson. 2006. Skin bioavailability of dietary vitamin E, carotenoids, polyphenols, vitamin C, zinc and selenium. Br. J. Nutr. 96:227-238.

Rodriguez-Lainz, A., P. Melendez-Retamal, D. W. Hird, D. H. Read, and R. L. Walker. 1999. Farm- and host-level risk factors for papillomatous digital dermatitis in Chilean dairy cattle. Prev. Vet. Med. 42:87-97.

Siciliano-Jones, J. L., M. T. Socha, D. J. Tomlinson, and J. M. DeFrain. 2008. Effect of trace mineral source on lactation performance, claw integrity, and fertility of dairy cattle. J. Dairy Sci. 91:1985-1995.

Siddiqui, M. M., S. J. Bartle, and R. L. Preston. 1993. Effects of iodine supplementation on selected immune measures of feedlot cattle. Texas Tech Univ. Tech Rep. No. T-5-327. Texas Tech University, Lubbock.

Somers, J. G., K. Frankena, E. N. Noordhuizen-Stassen, and J. H. Metz. 2005. Risk factors for digital dermatitis in dairy cows kept in cubicle houses in the Netherlands. Prev. Vet. Med. 71:11-21.

Son, E.-W., S.-R. Lee, H.-S. Choi, H.-J. Koo, J.-E. Huh, M.-H. Kim, and S. Pyo. 2007. Effects of supplementation with higher levels of manganese and magnesium on immune function. Arch. Pharm. Res. 30:743-749.

Spears, J. W. 1996. Organic trace minerals in ruminant nutrition. Anim. Feed Sci. Technol. 58:151-163.

Teixeira, A. G. V., V. S. Machado, L. S. Caixeta, R. V. Pereira, and R. C. Bicalho. 2010. Efficacy of formalin, copper sulfate, and a commercial footbath product in the control of digital dermatitis. J. Dairy Sci. 93:3628-3634.

Tenaud, I., S. Leroy, N. Chebassier, and B. Dreno. 2000. Zinc, copper and manganese enhanced keratinocyte migration through a functional modulation of keratinocyte integrins. Exp. Dermatol. 9:407-416.

Tomlinson, D. J., C. H. Mulling, and T. M. Fakler. 2004. Invited review: Formation of keratins in the bovine claw: Roles of hormones, 
minerals, and vitamins in functional claw integrity. J. Dairy Sci. 87:797-809.

USDA. 2009. Dairy 2007: Part V: Changes in Dairy Cattle Health and Management Practices in the United States, 1996-2007. USDA:Animal and Plant Health Inspection Service:Veterinary Services, Centers for Epidemiology and Animal Health (USDA:APHIS:VS, CEAH), Fort Collins, CO.

Walker, R. L., D. H. Read, K. J. Loretz, and R. W. Nordhausen. 1995 Spirochetes isolated from dairy cattle with papillomatous digital dermatitis and interdigital dermatitis. Vet. Microbiol. 47:343-355.

Wedekind, K. J., A. E. Hortin, and D. H. Baker. 1992. Methodology for assessing zinc bioavailability: Efficacy estimates for zinc-methionine, zinc sulfate, and zinc oxide. J. Anim. Sci. 70:178-187.

Wells, S. J., L. P. Garber, and B. A. Wagner. 1999. Papillomatous digital dermatitis and associated risk factors in US dairy herds. Prev. Vet. Med. 38:11-24.
Wirth, J. J., P. J. Fraker, and F. Kierszenbaum. 1984. Changes in the levels of marker expression by mononuclear phagocytes in zincdeficient mice. J. Nutr. 114:1826.

Wright, C. L., J. W. Spears, T. T. Brown, K. E. Lloyd, and M. E. Tiffany. 2000. Effects of chromium and copper on performance and immune function of stressed steers. J. Anim. Sci. 78(Suppl. 2):1. (Abstr.)

Zhang, J., and K. F. Yu. 1998. What's the relative risk? A method of correcting the odds ratio in cohort studies of common outcomes. JAMA 280:1690-1691.

Zhao, Y., W. Zhong, X. Sun, Z. Song, D. Clemens, Y. Kang, C. McClain, and Z. Zhou. 2011. Zinc deprivation mediates alcohol-induced hepatocyte IL-8 analog expression in rodents via an epigenetic mechanism. Am. J. Pathol. 179:693. 